\title{
Effect of Strut Geometry in Supersonic Mixing
}

\author{
V. Sumesh, P. Balachandran
}

\begin{abstract}
Effective mixing in a short mixing chamber is a major challenge in supersonic air breathing engines, especially the mixing between two high speed co-axial streams. The residence time is a major factor to get the two streams properly mixed. The selection of mixing method is crucial in the supersonic conditions. An experimental study has been performed on the supersonic mixing of air from strut injectors of various combinations in their trailing ramp angles with a free stream air of Mach number 2. Two different configurations of geometries, a plain geometry and a lobed geometry considered and further two different combinations, slot and hole injections, are taken for the study in each geometry. Among different combinations, it is found that a better mixing enhancement is achieved for the $9^{\circ}$ lobed geometry struts.
\end{abstract}

Keywords: Momentum Flux, Stagnation pressure loss, Strut injection, Supersonic mixing.

\section{INTRODUCTION}

The fuel injection, mixing, ignition, combustion and residence time are important activities in the scram jet engines since all these activities should be performed in the order of milliseconds. The combustion is mainly depending upon the effective mixing of two streams of high velocities in the case of such engines and hence the mode of mixing is of great importance. Active and passive methods are broadly used as mixing enhancements. In active methods, induction of turbulence, shock interactions, swirls etc. are generated by the active components like cavities or struts. In passive methods, the initial condition of the jet is changed by changing the nozzle geometry. A strut is a geometrical structure spans the entire width inside the nozzle along the primary stream. This will help the secondary stream, the fuel, directly injects into the core of the primary stream to enhance the uniform spreading of fuel in the lateral direction. More enhancements in mixing may be achieved if one can make necessary changes in the trailing ramp angles. Further advantages in the strut based injections are the formation of a recirculation zone, can be used, for flame holding combustion and the generation of vortices by ramps of the struts to accelerate the mixing.

Revised Manuscript Received on August 15, 2020.

* Correspondence Author

V. Sumesh*, Research Scholar, Department of Mechanical Engineering, College of Engineering Trivandrum, Thiruvanathapuram, India. E-mail: sumesh@cet.ac.in

P. Balachandran, Dean - Research, John Cox Memorial CSI Institute of Technology, Thiruvananthapuram, India. E-mail: pbalachandran2437@gmail.com

(C) The Authors. Published by Blue Eyes Intelligence Engineering and Sciences Publication (BEIESP). This is an open access article under the CC BY-NC-ND license (http://creativecommons.org/licenses/by-nc-nd/4.0/)
Majority of the secondary injections are performed by the wall injection, wall injection with cavity, and strut injection with ramps or wedges. Flow field structure and the mixing characteristics of the injectors by Schlieren technique is studied by Desikan et al. [1] using three different strut designs with straight and tapered ramps. The effect of strut geometry influences the generation of various sizes of vortices and changes in the shock system and the ignition conditions due to the presence of boundary layer along the wall in the combustion chamber is observed by Peter Gerlinger et al. [2]. The computational investigations by Naveen et al. [3] and Manu Ratnan et al. [4] showed very good mixing improvements with lobed struts. The capability to enhance the mixing in supersonic flows from struts with various trailing ramps were achieved by Sujith et al. [5] with a free stream air at Mach number 1.63 and a secondary air injection. Linguin HOU et al. [6] in their numerical analysis of multi staged injection found that the two stage injection makes full use of the residual oxygen near the wall and the second stage injection avoids the strong shock waves in the far downstream locations results a rising wall pressure and hence to achieve a good burning effects after the wall injection. This allows more fuel to be injected into the combustor without causing thermal choking. In this work a simulation of the non-reacting supersonic flow is generated to study the effect of wedge angle for the mixing effectiveness and total pressure loss of an intrusive secondary injection technique using wedge strut. Two streams of atmospheric air, one at a supersonic speed of 2 Mach supplied axially through a convergent divergent nozzle as a primary flow and the other one through a strut, which is fixed inside middle of the nozzle, supplied tangentially from both sides of the strut as a secondary flow allowed passing parallel to the main stream flow. The flow from the strut exit into the core of the main stream flow facilitates mixing of secondary and the primary streams in a mixing chamber as in Fig. 1. This intrusive method of the secondary stream allows proper mixing between two streams.

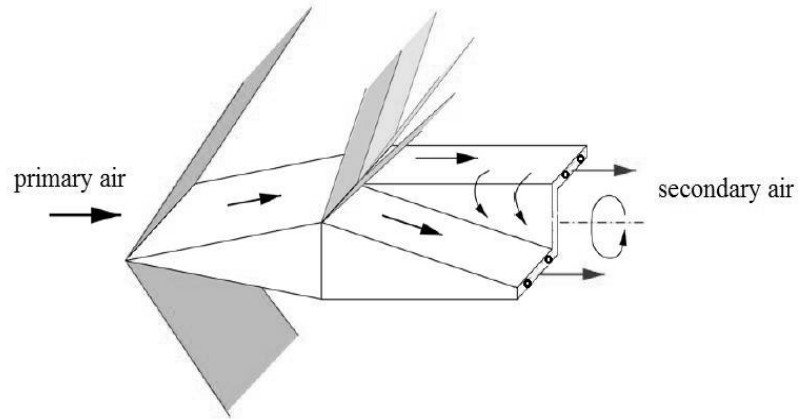

Fig. 1. Stream wise vortices created by the lobed strut

[2]
Blue Eyes Intelligence Engineering

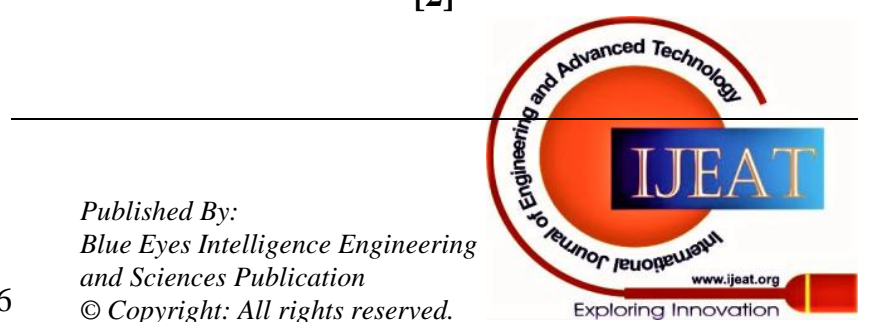




\section{Effect of Strut Geometry in Supersonic Mixing}

\section{MIXING PARAMETERS}

\section{A. Nomenclature}

\begin{tabular}{|ll}
\hline D & Degree \\
DOM & Degree of mixing \\
L/W & length to width ratio \\
X/h & position of the stagnation pressure probe at the \\
& ratio of horizontal to vertical \\
um & unmixed \\
$\Phi$ & Uniformity factor \\
$\mu$ & Momentum flux \\
\hline
\end{tabular}

\section{B. Momentum flux}

The supersonic jet from the nozzle enters into the mixer with different momentum and stagnation pressures. The momentum flux distribution at the exit of the mixing chamber in the lateral direction is the measure of the bulk mixing. Momentum flux is calculated [Z. A. Samitha et al. [7] as

$$
\mu=p\left(1+\gamma M^{2}\right)
$$

where $\mathrm{p}$ is the static pressure and $\mathrm{M}$ is the Mach number calculated from the measured values of stagnation pressure. The momentum flux at which uniformity attained indicates the axial distance where mixing is complete.

\section{Degree of mixing}

In order to compare the performance of mixing for different strut configurations based on a quantitative assessment of level of mixing achieved, a dimensionless parameter called uniformity factor $\Phi$ is defined as:

$$
\Phi=1-\left[\sigma_{\mu}(\mathrm{x}) / \mu_{\mathrm{av}}(\mathrm{x})\right]
$$

where $\sigma_{\mu}(\mathrm{x})$ is the standard deviation of radial distribution of momentum flux at a given axial location along the mixing chamber and $\mu_{\mathrm{av}}(\mathrm{x})$ is the average momentum flux along a lateral line at the location considered. Uniformity factor $\Phi$ is a measure of the uniformity of the momentum flux distribution in the lateral direction at a given location. For a properly mixed flow, the distribution has to be uniform across the section. A mixing parameter called degree of mixing (DOM) is defined, using the uniformity factor, as:

$$
\mathrm{DOM}=\left(\Phi-\Phi_{\mathrm{um}}\right) /\left(1-\Phi_{\mathrm{um}}\right)
$$

where $\Phi_{\text {um }}$ is the values of $\Phi$ when the two streams are totally unmixed and DOM will be zero.

\section{EXPERIMENTAL SETUP}

A schematic of the experimental setup is shown in Fig. 2. The setup consists of a high pressure compressor and the storage vessels of 3000 litres of total capacity. The exit air from the storage is maintained for $8 \mathrm{bar}$, which is supplied as the main stream air to the nozzle. A secondary supply line is made for the air supply through the strut, which is placed inside the nozzle.

\section{A. Rectangular nozzle}

A rectangular convergent divergent nozzle is made with the help of gas dynamic relations by considering the main stream pressure and the static pressure corresponding to the atmospheric conditions. The throat and the exit areas of the nozzle is calculated and the convergent angle is considered here as $13^{\circ}$, following the conventional practice. Fig. 3 shows the rectangular convergent divergent nozzle.

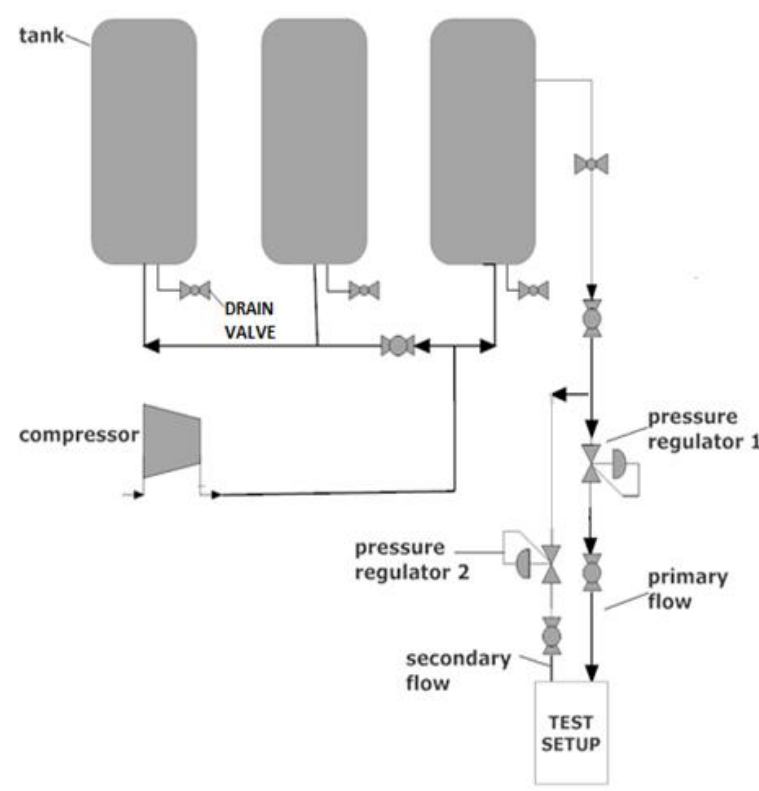

Fig. 2. Schematic of the experimental setup

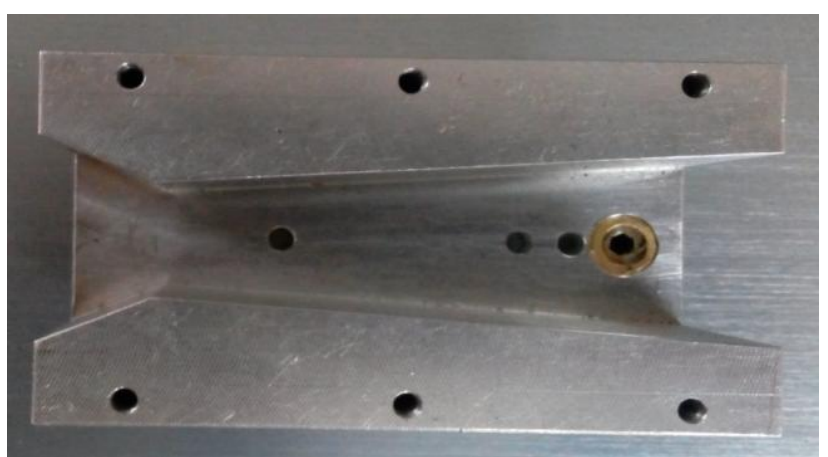

Fig. 3 Rectangular convergent divergent nozzle

\section{B. Strut geometry}

Based on the available duct area to maintain the supersonic flow, the strut dimensions are decided. An alternate wedge unswept strut is chosen. There are two upward wedges and one downward wedge at the middle in the lobed struts as in Fig. 4.(a) and (b). and in Fig. 5 (a) and (b) as per the details in Table. I.

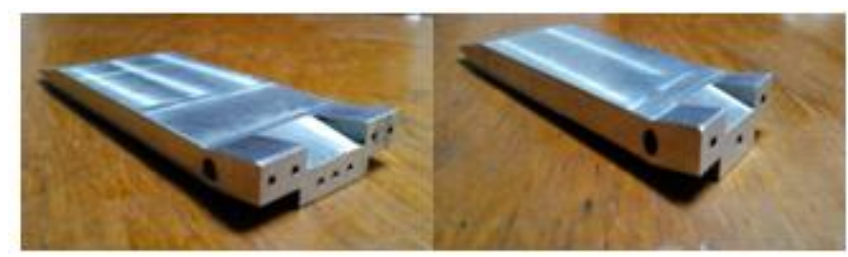

Fig. 4 (a) Lobed strut with holes (b) Lobed struts with slots

The strut occupies the full width of flow channel, as shown in Fig. 6, thereby dividing the flow equally in the subsonic region itself. The flow in the upper and lower portion of the strut flows without any deflection up to the starting of the wedges. In the upper compartment, the cross sectional area just above the upward bend portion reduces and pushes the air to the middle section. Likewise for the lower compartment.

Published By:

Blue Eyes Intelligence Engineering

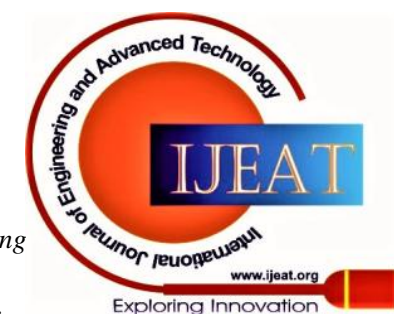




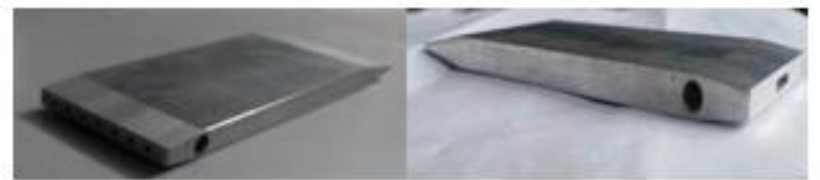

Fig. 5 (a) Planar strut with holes (b) planar struts with slots

Table I. Strut configurations

\begin{tabular}{|c|c|c|}
\hline Strut Goemetry & $\begin{array}{c}\text { Strut exit } \\
\text { configuration }\end{array}$ & Sumber of exits \\
\hline Planar strut & Slot & Single \\
\hline Lobed Strut & Slot & holes \\
\hline Planar strut & Holes & $\begin{array}{l}\text { 3 holes in the middle lobe } \\
\text { and 2 holes each in the } \\
\text { other two lobes }\end{array}$ \\
\hline Lobed Strut & Holes & \\
\hline
\end{tabular}

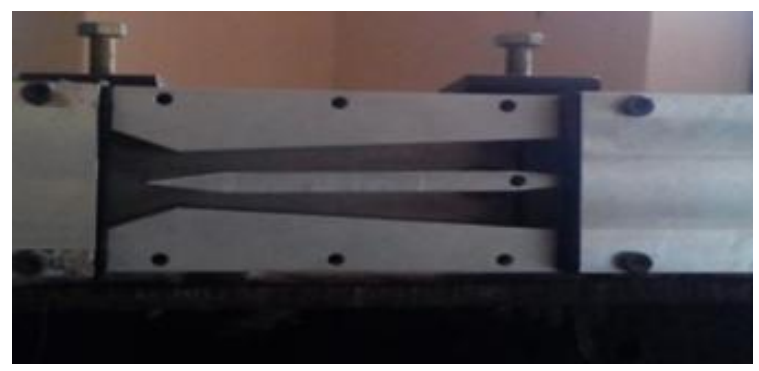

Fig. 6 nozzle and strut assembly

\section{Test setup}

The primary and secondary air supplies were equipped as shown in Fig. 7 with pressure regulators to control the pressure from the stored vessels to the required pressure for performing the experiment. A pressure probe is fitted with a three way traversing mechanism was used for measuring stagnation pressure at various points at the exit of the mixing chamber.

\section{Mixing Chamber}

Mixing chambers of aspect ratio $\mathrm{l} / \mathrm{w}=5$ was fabricated with necessary provisions to measure the static and stagnation pressure. The length of the mixing chamber was $154 \mathrm{~mm}$.

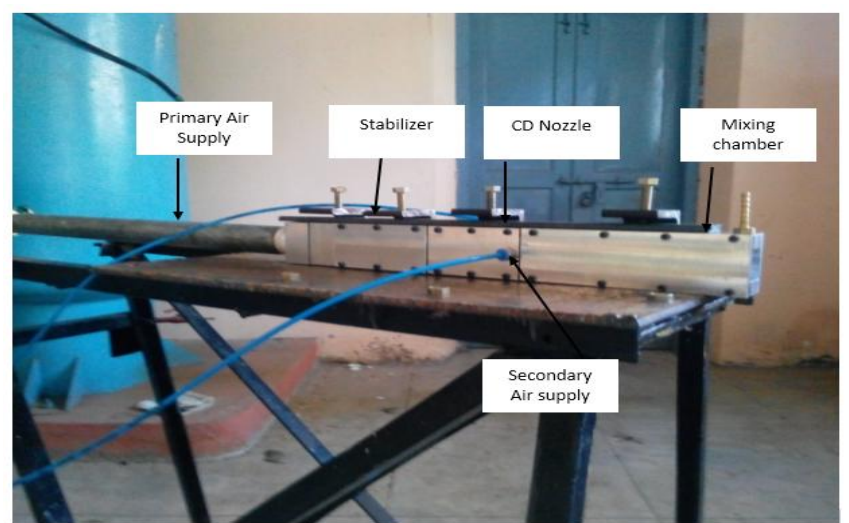

Fig. 7 Test setup

\section{E. Experimental procedure}

The experiments were conducted by applying same boundary conditions and procedure for all strut configurations. The air was compressed and stored at 20 bar. The stored air was allowed to flow through the main stream line with a pressure of 8 bar and the secondary line with a pressure of 2 bar respectively by controlling the pressure regulating valves. The digital manometers were used to record the static and stagnation pressure. More stagnation pressure readings are taken with the help of a three way traversing mechanism.

\section{RESULT AND DISCUSSION}

\section{A. Momentum flux}

The momentum flux distribution of various strut configurations are shown in Fig.8, 9, 10, 11, and 12. The flatness characteristics of the momentum flux show the mixing uniformity along transverse direction. The momentum flux distributions were more flat in lobed struts than that of the planar struts. This indicates the lobed strut is better in mixing. Fig. 8 shows the momentum flux distributions of planar and 9 degree lobed struts with slots whereas Fig. 10 shows that of struts with holes. A flat characteristic in the curves of both the lobed strut geometry shows its improvement in mixing. Moreover, the hole geometry exhibit a very good mixing efficiency. In Fig. 9, a comparison of numerical (Manu Ratnan et al. 2014) and experimental results presented for the slot configuration. Both planar and lobed struts very closely match their results in numerical as well as in the experimental approaches. Therefore the numerical approach can be considered valid with the experimental outcomes and the 9 degree lobed strut with slot shows more efficient in mixing in the experimental result of slot combination.

Similarly a comparison of numerical (Naveen et al. 2014) and experimental results presented in Fig. 11 for the struts with hole configuration. Here the numerical and experimental results of 9 degree lobed struts exactly match with each other.

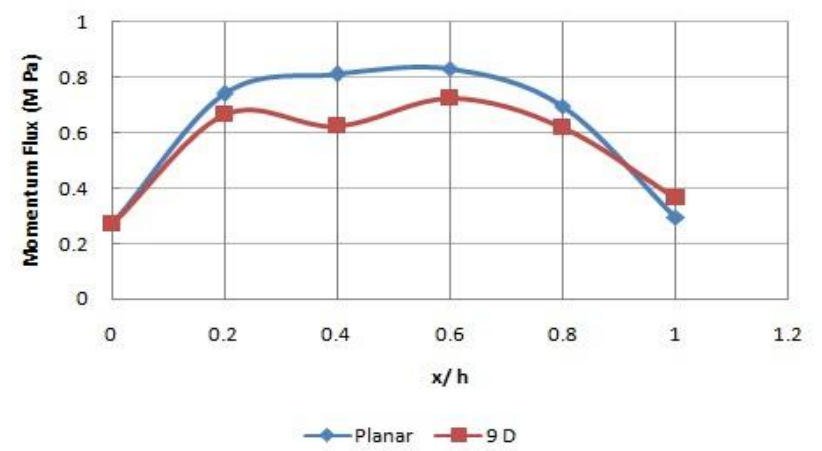

Fig.8. Momentum flux distribution of struts with slots

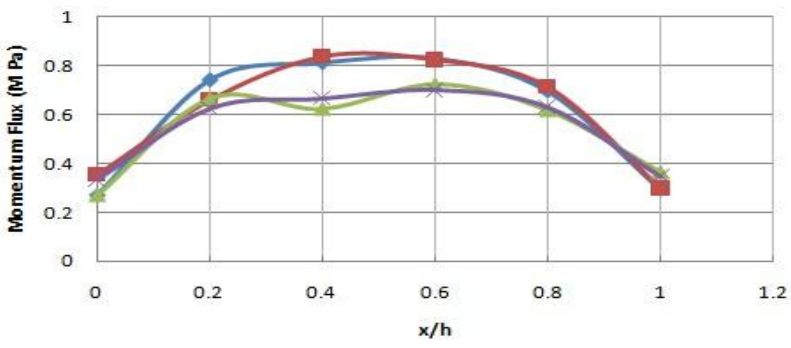

$\multimap$ Planar Numerical $\rightarrow$-planar Exptl $\rightarrow-9 \mathrm{D}$ Numerical $\multimap 9 \mathrm{DExptl}$

Fig. 9.Numerical and experimental comparison for struts with slots

Published By:

Blue Eyes Intelligence Engineering and Sciences Publication (C) Copyriqht: All rights reserved.

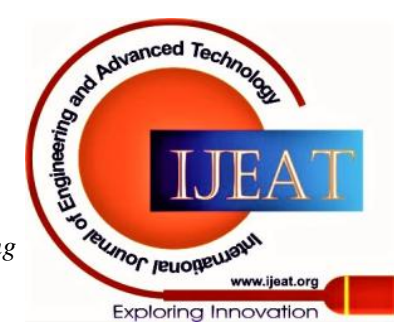




\section{Effect of Strut Geometry in Supersonic Mixing}

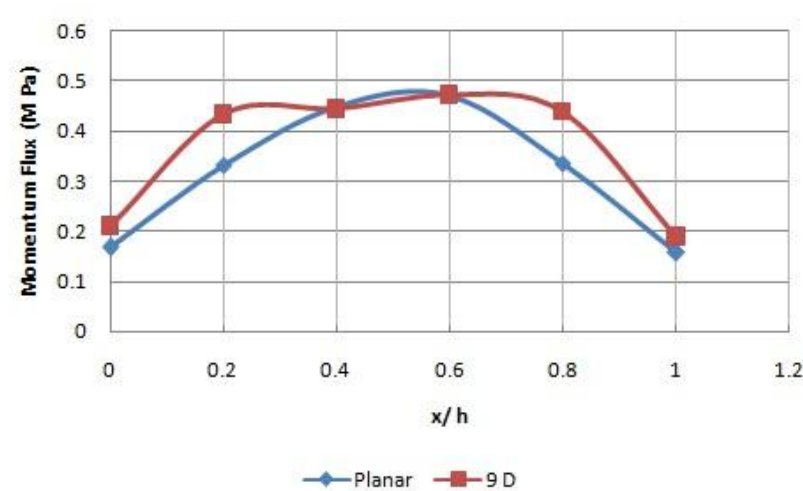

Fig. 10. Momentum flux distribution of struts with holes

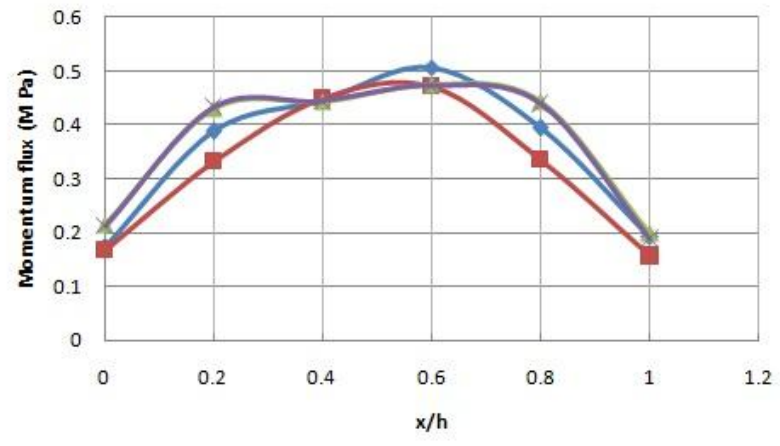

$\leadsto$ Planar Numerical - -Planar Exptl $\rightarrow 9$ D Numerical $\multimap 9$ D Exptl

Fig. 11. Numerical and experimental comparison of struts with holes

\section{B. Degree of mixing}

From the analysis of results the degree of mixing for different strut configurations are given in Table II below. Among these four configurations, 9 degree lobed strut geometries showed better DOM, which contributes that, the mixing enhancement by the lobed geometry

Table II. Degree of mixing

\begin{tabular}{|c|c|c|}
\hline Strut Goemetry & $\begin{array}{c}\text { Strut exit } \\
\text { configuration }\end{array}$ & DOM \\
\hline Planar strut & Slot & $57 \%$ \\
\hline $9^{\circ}$ Lobed Strut & Slot & $66.5 \%$ \\
\hline Planar strut & Holes & $61 \%$ \\
\hline $9^{\circ}$ Lobed Strut & Holes & $65 \%$ \\
\hline
\end{tabular}

\section{CONCLUSION}

Experimental investigations to study the mixing characteristics of different strut geometries were carried out. Strut with slot and hole configurations inserted in to the nozzle of the same throat area and the same mixing chamber used. The conclusions drawn from the study and analysis are as follows

- The momentum flux distribution in lateral direction at an axial location of $\mathrm{L} / \mathrm{W}=5$ for different strut geometries analyzed and the results indicated the 9 degree lobed struts had better mixing with 65\% and 66.5\% DOM, which is higher than the planar configurations.

- DOM with higher value obtained in lobed struts indicates that they are efficient in mixing.

The comparison of numerical results published for these configurations with experimental results indicates better match with each other, which shows the numerical method taken for the present evaluation, was appropriate.

\section{REFERENCES}

1. Desikan S. L. N and Job Kurian, "Mixing studies in Supersonic Flow Employing Strut Based Hypermixers", $41^{\text {st }}$ AIAA/ASME/SAE/ASEE Joint propulsion Conference and Exhibit, AIAA 2005-3643.

2. Peter Gerlinger, Peter Stoll, Markus Kindler, Fernando Schneider and Manfred Aigner., "Numerical Investigation of Mixing and Combustion Enhancement in supersonic Combustors by Strut induced Streamwise Vorticity", Aerospace Science and Technology, 12, 2008, 159-168

3. Naveen P. R., Sumesh V., Zamitha Z. A., P. Balachandran, "CFD Analysis of Supersonic mixing using strut with holes", National Conference on Technological Trends (NCTT) August 2014, Paper ID 22390

4. Manu Ratnan, Sumesh V.,Dr. P. Balachandran, Dr. Samitha Z. A. "Numerical Investigation of Supersonic Mixing Using Planar and Lobbed Struts with slot", National Conference on Technological Trends (NCTT) August 2014, Paper ID 22391

5. Sujith S., Muruganandanam, T. M., and Job Kurian, "Effect of Trailing Ramp Angles in Strut Based Injection in Supersonic Flow", Journal of Propulsion and Power, 2013, vol. 29 (1), pp 66 - 78.

6. Lingyun HOU, Bernhard WEIGAND, Marius BANICA, "Effects of Staged Injection on Supersonic mixing and Combustion", Chinese Journal of Aeronautics, 2011, vol.24, pp 584 - 589

7. Z. A. Samitha, B. Swaraj Kumar, P. Balachandran, "Experimental Study on Supersonic Mixing Using Clover Nozzle", 45 $5^{\text {th }}$ AIAA Aerospace Sciences Meeting and Exhibit, AIAA 2007-839.

\section{AUTHORS PROFILE}

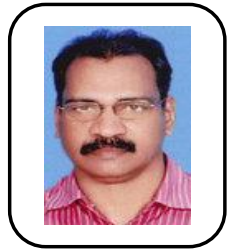

V. Sumesh is the Research scholar in Kerala Univrsity and Associate professor in College of Engineering Trivandrum. He has more than 10 years experience in various Industries and more than 17 years experience in teaching. Presently he is doing research works on supersonic mixing. He has published more than 10 research papers in international and national conferences. He has supervised the research works of 10 M.Tech students. His areas of interest include combustion, fluid dynamics and heat transfer.

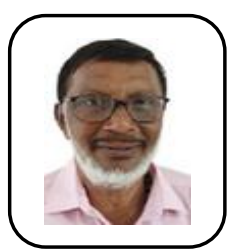

P. Balachandran was a Senior Scientist and Deputy Divisional Head of LPSC, ISRO, Thiruvananthapuram, India. He has completed his $\mathrm{Ph}$ D. from IIT Madras. He has also worked as Assistant Professor for 12 years at TKMCE, Kollam, Principal at Travancore Engineering College, Kollam and John Cox Institute of Technology, Thiruvananthapuram. At present he is the Dean-Research at John Cox Institute of Technology. He has published more than fifty research papers in international and national journals and conferences. His areas of interest include fluid dynamics, combustion and heat transfer. He is the author of the text book "Fundamentals of Compressible Fluid Dynamics (ISBN-978-81-203-2857-0).

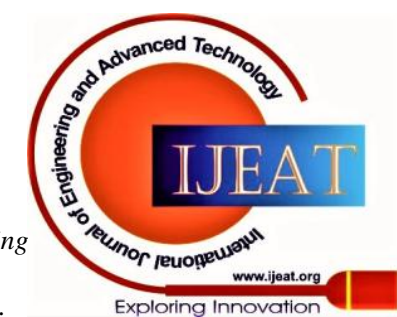

